\title{
Position paper on the use of mandibular advancement devices in adults with sleep-related breathing disorders
}

\author{
A position paper of the German Society of Dental Sleep Medicine (Deutsche Gesellschaft \\ Zahnaerztliche Schlafmedizin, DGZS)
}

\author{
Susanne Schwarting • Ulrich Huebers • Markus Heise • \\ Joerg Schlieper • Andreas Hauschild
}

Published online: 27 April 2007

(C) Springer-Verlag 2007

\begin{abstract}
Custom-made mandibular advancement devices are an effective treatment option for snoring, upper airway resistance syndrome, and obstructive sleep apnea (OSA). Evidence-based data indicates their efficacy, and international sleep societies recommend oral appliance (OA) therapy for patients with sleep-related breathing disorders. The following position paper by the German Society of Dental Sleep Medicine (DGZS) is to guide the interdisciplinary team (sleep physician and sleep disorder dentist) in detail when to prescribe oral appliances. This position paper supports the responsible use of OA as an effective treatment option for patients with sleep-related breathing disorders. The paper advises of proper indication regarding OSA
\end{abstract}

DGZS board:

Susanne Schwarting, DDS (Dentist, Kiel);

Ulrich Huebers, DDS (Orthodontist, Offenburg);

Markus Heise, DDS (Orthodontist, Herne);

Joerg Schlieper, MD DDS (Maxillofacial Surgeon, Hamburg);

Andreas Hauschild, DDS (Orthodontist, Heilbronn)

\author{
S. Schwarting $(\bowtie)$ \\ Andreas-Gayk-Strasse 23, \\ 24103 Kiel, Germany \\ e-mail: praxis@drschwarting.de \\ U. Huebers \\ Offenburg, Germany \\ M. Heise \\ Herne, Germany \\ J. Schlieper \\ Hamburg, Germany \\ A. Hauschild \\ Heilbronn, Germany
}

severity, body mass index (BMI), and dentition. It emphasizes the interdisciplinary approach of oral appliance therapy and suggests treatment under the guidance of dentists trained in dental sleep medicine.

Keywords Position paper-Mandibular advancement device - Oral appliance $\cdot$ Dental sleep medicine $\cdot$ Obstructive sleep apnea $\cdot$ Upper airway resistance syndrome $\cdot$ Snoring . DGZS · German Society of Dental Sleep Medicine

\section{Introduction}

Various options are available in the treatment of obstructive sleep-related breathing disorders (SRBD):

- Continuous or bi-level positive airway pressure (nCPAP/biPAP)

- Mandibular advancement devices (MADs)

- Surgical procedures

- Other procedures

The use of oral appliances in treating SRBD was first described in 1982 [3]. The first findings, which document the therapeutic effect of MADs, were presented in 1984 [8]. Of the many oral appliances designed for use in the treatment of SRBD, mandibular advancement devices have been the most intensely researched. Progress in the areas of dentistry and appliance technology has lead to fundamental modifications in the design of mandibular advancement devices.

The clinical effectiveness of this treatment option has been documented with varying degrees of evidence in numerous studies. The clinical importance of this form of therapy is constantly being reinforced by the gathering of 
improved data on the validity of this form of treatment. The effectiveness of mandibular advancement devices in the treatment of SRBD has been documented by the Cochrane Collaboration as the highest level of scientific evidence [5]. The clinical analysis has been reviewed and revised twice since Cochrane's first evaluation in 2002 [6, 7]. The German Society of Dental Sleep Medicine (DGZS) takes this opportunity to issue its position with regard to this form of therapy and to make recommendations.

\section{The definition of mandibular advancement devices in the treatment of SRBD}

A system of laboratory fabricated custom-made adjustable splints manufactured for the individual patient and adjusted to fit the upper and lower jaws. These splints position the lower jaw, tongue, and additional structures more anteriorly, and increase the occlusal vertical dimension, resulting in an opening of the pharynx lumen, which reduces resistance in the airway and mechanically keeps the airway open during sleep.

\section{Guidelines and indication recommendations from professional sleep-medicine societies}

As early as 1995, the American Academy of Sleep Medicine (AASM) published recommendations on the indication and application of oral appliances in the treatment of SRBD [1]. These were updated and stated more precisely in 2005 [2]. In 2001, the German Society of Pneumology (DGP) in co-operation with the German Sleep Society (DGSM) published the "S2" guidelines on the diagnosis and treatment of SRBD. These guidelines envisaged the use of mandibular advancement devices as a treatment option [4]. A new description of the significance of mandibular advancement devices was formulated by the "Task Force Apnea of the DGSM" in the year 2006 [9].

Based on scientific appraisals and international guidelines, the DGZS recommends the use of mandibular advancement devices in the treatment of SRBD:

1. As an initial treatment for

- Primary snoring

- Upper airway resistance syndrome

- Mild to moderate obstructive sleep apnea [apnea hypopnea index (AHI) up to about 25/h] with minor clinical symptoms with a sufficient number of retaining teeth and a body mass index (BMI) of up to $30 \mathrm{~kg} / \mathrm{m}^{2}$
2. In cases of SRBD with an approximate AHI of over $25 / \mathrm{h}$, MADs can be used as an alternative after a previous therapeutic trial with nCPAP.

3. Regardless of SRBD severity in patients with CPAP failure and CPAP noncompliance.

4. A special dental, oral, and functional diagnosis is necessary to check the dental requirements for longterm use before prescribing MADs.

5. The procedure should take into account the various interdisciplinary and intradisciplinary treatment flows, particularly the preliminary medical diagnosis and the subsequent medical follow-ups.

6. This service should be delivered by dentists who have specialized training in the field of sleep medicine.

The DGZS supports the specialized training of dentists and physicians in the field of dental sleep medicine. Patients and referring physicians can find the addresses of certified practitioners on the DGZS website at http://www. dgzs.de.

\section{References}

1. American Academy of Sleep Medicine (1995) Practice parameters for the treatment of snoring and obstructive sleep apnea with oral appliances. Sleep 18:501-510

2. American Academy of Sleep Medicine (2006) An American Academy of Sleep Medicine report. Practice parameters for the treatment of snoring and obstructive sleep apnea with oral appliances: an update for 2005. Sleep 29:240-243

3. Cartwright RD, Samelson CF (1982) The effects of a nonsurgical treatment for obstructive sleep apnea. The tongue-retaining device. JAMA 248:705-709

4. Fischer J, Mayer G, Peter J-H, Riemann D, Sitter H (2002) Leitlinie "S2" der Deutschen Gesellschaft für Schlafforschung und Schlafmedizin (DGSM). Nicht erholsamer Schlaf. Blackwell Wissenschafts-Verlag, Berlin, Wien

5. Lim J, Lasserson TJ, Fleetham J, Wright J (2006) Oral appliances for obstructive sleep apnoea. Cochrane Database Syst Rev, CD004435

6. Lim J, Lasserson TJ, Fleetham J, Wright J (2004) Oral appliances for obstructive sleep apnoea. Cochrane Database Syst Rev, CD004435

7. Lim J, Lasserson TJ, Fleetham J, Wright J (2003) Oral appliances for obstructive sleep apnoea. Cochrane Database Syst Rev, CD004435

8. Meyer-Ewert K, Schäfer H, Kloß W (1984) Treatment of sleep apnea by mandibular protracting device. 7th European congress of sleep research, München, p 217

9. Randerath W, Bauer M, Blau A, Fietze I, Galetke W, Hein H, Maurer JT, Orth M, Rasche R, Rühle KH, Sanner B, Stuck BA, Verse T (2006) Stellenwert der Nicht-nCPAP-Verfahren in der Therapie des obstruktiven Schlafapnoe-Syndroms. Somnologie 10:67-98 